\title{
Vivência de Mulheres Jovens diante da Neoplasia Mamária
}

doi: https://doi.org/10.32635/2176-9745.RBC.2020v66n4.1059

\section{Experience of Young Women in face of Breast Neoplasia \\ Experiencia de Mujeres Jóvenes frente al Cáncer de Mama}

Ana Paula Alonso Reis Mairink'; Clícia Valim Côrtes Gradim²; Maria Antonieta Spinoso Prado³; Marislei Sanches Panobianco4

\section{RESUMO}

Introdução: A neoplasia mamária requer tratamentos que alteram a autoimagem e autoestima da mulher. As modificaçôes corporais ocasionam impacto na esfera física, emocional e social, especialmente nas mulheres jovens. Objetivo: Compreender a vivência de mulheres jovens (18 a 40 anos) em tratamento da neoplasia mamária. Método: Estudo qualitativo, com referenciais teórico e metodológico: interacionismo simbólico e teoria fundamentada nos dados. Participaram da pesquisa 13 mulheres. Os dados foram coletados em dois Centros de Assistência de Alta Complexidade em Oncologia, entre outubro/2017 e agosto/2019, com a pergunta norteadora: "Conte-me sobre sua experiência de vivenciar o câncer de mama”. Resultados: A metodologia propiciou a geração da categoria "O câncer de mama e suas repercussóes para a mulher jovem" e da subcategoria "Aspectos emocionais e físicos modificando as relaçóes sociais". Conclusáo: Destaca-se que a perda da vaidade nesse grupo jovem foi o ponto mais marcante e veio associado à alopecia, à mastectomia e ao déficit de autonomia, com prejuízo de atividades laborais.

Palavras-chave: Neoplasias da Mama; Mastectomia; Imagem Corporal; Alopecia/tratamento farmacológico; Autoimagem.

\section{ABSTRACT}

Introduction: Breast cancer requires treatments that change a woman's self-image and self-esteem. Body changes have an impact on the physical, emotional and social spheres, especially in young women. Objective: To understand the experience of young women (18 to 40 years old) in treatment of breast cancer. Method: Qualitative study, with theoretical and methodological references: symbolic interactionism and grounded theory. Thirteen women participated in the research. Data were collected in two High Complexity Assistance Centers in Oncology, between October/2017 and August/2019, with the guiding question: "Tell me about your experience of living with breast cancer". Results: The methodology led to the generation of the category "Breast cancer and its repercussions for young women" and the subcategory "Emotional and physical aspects modifying social relationships". Conclusion: The loss of vanity in this young group was the most striking point and was associated with alopecia, mastectomy and autonomy deficit in with impairment of work activities.

Key words: Breast Neoplasms; Mastectomy; Body Image; Alopecia/drug therapy; Self Concept.

\section{RESUMEN}

Introducción: El cáncer de mama requiere tratamientos que alteren la autoimagen y la autoestima de una mujer. Los cambios corporales tienen un impacto en las esferas física, emocional y social, especialmente en las mujeres jóvenes. Objetivo: Comprender la experiencia de las mujeres jóvenes (18 a 40 ańos) en el tratamiento del cáncer de mama. Método: Estudio cualitativo, con referencias teóricas y metodológicas: interaccionismo simbólico y teoría fundamentada. Trece mujeres participaron en la investigación. Los datos fueron recolectados en dos Centros de Asistencia de Alta Complejidad en Oncología, entre octubre/2017 y agosto/ 2019, con la pregunta guía: "Cuénteme sobre su experiencia de experimentar cáncer de seno”. Resultados: La metodología condujo a la generación de la categoría "Cáncer de mama y sus repercusiones para las mujeres jóvenes" y la subcategoría "Aspectos emocionales y físicos que modifican las relaciones sociales". Conclusión: La pérdida de la vanidad en este grupo joven fue el punto más llamativo y se asoció con alopecia, mastectomía y un déficit de autonomía con deterioro de las actividades laborales.

Palabras clave: Neoplasias de la mama; Mastectomía; Imagen Corporal; Alopecia/tratamiento farmacológico; Autoimagen. 


\section{INTRODUÇÃO}

No Ocidente, as mamas simbolizam sexualidade e feminilidade. Assim, a neoplasia mamária pode ser estigmatizante para as mulheres, em especial para as jovens, por estarem em uma etapa de importante estabelecimento de relaçóes sociais, pessoais e afetivas.

É inegável a supervalorização do corpo na sociedade moderna, sendo utilizado como instrumento de obtenção de poder e inclusão social. A busca incessante pelo corpo esbelto e belo é estimulada pela indústria da beleza e vale tudo para conseguir se adequar aos padróes preestabelecidos, como a colocaçáo de prótese de silicone, realização de cirurgias plásticas, uso de anabolizantes, entre outros. Aqueles que não se encaixam no perfil estético acabam se tornando vítimas de marginalização e preconceito, sendo esse fato agravado quando as alteraçôes corporais são provenientes de procedimentos médicos associados a enfermidades, como no câncer de mama ${ }^{1}$.

Nesse sentido, cabe salientar que a neoplasia mamária requer tratamentos que levam à alteraçáo da autoimagem e da autoestima da mulher, especialmente as modalidades cirúrgica $^{2}$ e quimioterápica ${ }^{3}$, por causarem a perda total ou parcial da mama e a queda dos cabelos e pelos do corpo, fatores que podem interferir na sexualidade e levar a mulher à dificuldade de se relacionar sexualmente com seu companheiro ${ }^{4}$.

O termo imagem não se refere somente ao sentido específico da visão, mas também compreende vivências sociais, fisiológicas e afetivas que influenciam o modo como o sujeito se percebe. A figura do corpo não vem apenas do imaginário, mas também do simbólico, sendo uma ideia enigmática que necessita ser codificada ${ }^{1}$.

Assim, é esperado que as modificaçôes corporais, advindas dos tratamentos para a neoplasia mamária, ocasionem impacto não só na esfera física, mas também na emocional e na social, em especial nas mulheres jovens.

Essas pacientes jovens se veem diante da necessidade de mudar a visão de sua vida, superar as desvantagens mentais e o estresse da doença, precisando de ajuda para isso, pois não conseguem fazê-lo sozinhas ${ }^{5}$. O diagnóstico de câncer de mama, em uma mulher jovem, acarreta mudança inesperada em sua trajetória de $v i_{a}{ }^{5}$, em especial, nas questóes relacionadas com a aparência e no relacionamento com seu companheiro ${ }^{6}$.

Os estudos tendem a ser realizados com mulheres com mais de 50 anos, uma vez que a incidência de diagnóstico de câncer de mama aumenta com a idade. Sáo poucos os estudos que abordam o público mais jovem. Esta pesquisa foi composta por mulheres jovens ${ }^{7,8}$; ou seja, aquelas que possuem até 40 anos.
Apesar do grande interesse no impacto psicológico do diagnóstico e no tratamento da neoplasia mamária, os achados não são totalmente conclusivos, pois a maioria das investigações é conduzida considerando mulheres com mais de 50 anos. Assim, o objetivo deste estudo foi compreender a vivência de mulheres jovens (18 a 40 anos) em tratamento da neoplasia mamária.

\section{MÉTODO}

Estudo de abordagem qualitativa, cujo referencial teórico foi o interacionismo simbólico (IS), e o metodológico, a teoria fundamentada nos dados (TFD).

O IS permite compreender e interpretar a conduta humana por meio do entendimento de conceitos como símbolos, self, mente, interação social e sociedade, que foram retratados por $\mathrm{Mead}^{9}$ e esclarecidos por Blumer ${ }^{10}$ em 1937.

Conforme a perspectiva do IS, são considerados símbolos os gestos, as expressóes faciais e corporais, os objetos e as falas; ou seja, aquilo que possibilita aos seres humanos a comunicação, seja essa verbal ou não verbal, advinda da interação social. O self, definido como o ego/a própria pessoa, é o elemento com o qual as pessoas agem, sendo dividido nas fases eu (meus atos são involuntários) e mim (meus atos são correspondentes à interpretação que eu faço do que os outros pensam sobre mim). A mente é o lugar onde se interpretam os símbolos que são assimilados durante a comunicação social, já na sociedade acontecem as interações humanas, que podem definir e/ou modificar os nossos atos ${ }^{9,10}$.

A TFD é um referencial metodológico que possibilita o conhecimento, o entendimento e a interpretação dos fenômenos que ocorrem, sejam estes no presente ou no passado. Foi desenvolvida por Barney e Strauss, no início da década de $1960^{11}$, sendo que, posteriormente, por divergência quanto aos preceitos metodológicos, esses autores se separaram e Strauss fez parceria com Corbin ${ }^{11-14}$. Por isso, este trabalho seguiu os preceitos metodológicos contemplados na obra publicada em 2008 por Strauss e Corbin $^{11}$.

Os locais de coleta de dados foram dois Centros de Assistência de Alta Complexidade em Oncologia (Cacon). Um deles localizado na Região Sudeste do Estado de São Paulo (Cacon A); e o outro, na Região do Sul do Estado de Minas Gerais (Cacon B).

Os critérios de inclusão foram mulheres diagnosticadas com câncer de mama há no máximo um ano, que estavam realizando tratamento para a doença, com idades entre 18 e 40 anos e que possuíam companheiro sexual desde o diagnóstico para a doença. Já o critério de exclusão foi mulheres que estivessem em cuidados de fim de vida. 
Realizou-se teste-piloto em outubro/2017. Os dados foram coletados entre outubro/2017 e agosto/2019, por meio de entrevista gravada (áudio), com tempo médio de duração de 28 minutos e registro em diário de campo, tendo como questáo norteadora: "Conte-me sobre sua experiência de vivenciar o câncer de mama". Tanto as entrevistas quanto a transcrição manual e análise de dados foram conduzidas por uma das autoras. A validaçáo da teoria ocorreu por uma participante da pesquisa (E8) e duas expertises, uma da metodologia e outra da temática.

Participaram da pesquisa 13 atrizes sociais; não houve desistências e nem repetição das entrevistas, que se encerraram a partir da compreensão do fenômeno e da repetição de informaçóes, sem o acréscimo de elementos que trouxessem novos aspectos de significância para o entendimento do objeto em estudo.

A seleção da amostragem foi intencional, com levantamento de dados em prontuários. As mulheres foram convidadas a participarem da pesquisa nos dias e horários que estavam realizando alguma das modalidades de tratamento para o câncer, nos referidos Cacon onde a pesquisa ocorreu, sendo a inserçáo da pesquisadora no Cacon B de modo gradual, no início da coleta; e, no Cacon $\mathrm{A}$, o vínculo com o serviço existia anteriormente, quando foram coletados os dados de sua pesquisa de mestrado. Mediante esclarecimentos sobre o estudo, retirada de dúvidas, garantia de sigilo, liberdade de recusar e deixar de participar da pesquisa a qualquer momento, as mulheres assinaram o Termo de Consentimento Livre e Esclarecido (TCLE), e a entrevista ocorreu em um local que preservou sua privacidade.

O estudo foi aprovado pelos Comitês de Ética em Pesquisa sob os números 69123517.2.0000.5393 e 69123517.2.3002.8043. Assim, todas as orientaçôes estabelecidas pela Resoluçáo do Conselho Nacional de Saúde (CNS) número 466, de 12 de dezembro de 2012 ${ }^{15}$, foram atendidas para a condução da pesquisa.

A TFD ${ }^{11}$ possui três etapas de análise de dados. $\mathrm{Na}$ primeira etapa, codificação aberta, realiza-se a leitura das entrevistas transcritas com foco para a identificação dos códigos abertos (semelhantes), aos quais são atribuídas frases/expressóes com a intuito de delimitar e visualizar os dados que estão emergindo. Na segunda etapa, codificação axial, esses códigos abertos, identificados na primeira etapa da análise, devem ser agrupados em subcategorias e categorias, permitindo visualizar o fenômeno que está sendo desvelado e aproximar o pesquisador com seu objeto de estudo, além da reflexão sobre os dados que emergem da pesquisa (sensibilidade teórica) e a busca na literatura por elementos que auxiliam nessa compreensão.

A terceira etapa de análise dos dados, a seletiva, nos possibilita a construção de uma teoria mediante o refinamento e a integração das categorias e subcategorias elaboradas anteriormente, permitindo que os resultados da pesquisa assumam a forma de TFD, o que é endossado por meio da validaçáo do estudo pelos participantes da pesquisa e expertises da área. ATFD permite um constante ir e vir aos dados (circularidade), de modo que é admissível retornar a uma das etapas de análise dos dados, a qualquer momento, e refazê-la, no intuito de identificar lacunas que ainda precisam ser preenchidas até o entendimento completo do objeto de estudo e a conclusão da coleta de dados (elaboraçáo de hipóteses para o preenchimento de categoria e subcategoria ao longo de suas propriedades, dimensôes e variaçôes).

Todas essas etapas da metodologia nos direcionam para a construção do diagrama (Figura 1) que é a representação gráfica das categorias e subcategorias do estudo.

\section{RESULTADOS}

A média da faixa etária das atrizes sociais foi 37,1 anos, com concentração de 39 a 40 anos. Dessas mulheres, $53,84 \%$ são evangélicas; e $61,55 \%$ possuíam o ensino médio completo. Em relação à ocupação, 15,38\% eram do lar e $84,62 \%$ estavam inseridas no mercado de trabalho, realizando atividades diversas. Quanto à cor, autodeclararam-se pardas $46,15 \%$ e $84,62 \%$ casadas ou em união estável; $15,38 \%$ declararam-se solteiras e com namorado. Sobre a mama afetada, houve predomínio da lateralidade na mama direita, com 53,85\%. Todas apresentavam carcinoma ductal infiltrante, em estádios IIB e IIIA, tipo esperado por se tratar de mulheres jovens. $\mathrm{Na}$ coleta de dados, 53,85\% não haviam realizado o procedimento cirúrgico para a remoção do nódulo mamário. Quanto às modalidades de tratamento, 92,30\% dessas mulheres estavam realizando quimioterapia, $30,77 \%$ radioterapia e $15,38 \%$ hormonioterapia com tamoxifeno. E ainda, 53,85\% referiram amenorreia em decorrência dos tratamentos sistêmicos.

Seguindo os preceitos de Strauss e Corbin ${ }^{11}$, as duas primeiras etapas da análise dos dados (codificaçôes aberta e axial) levaram-nos à construção dos códigos abertos e seus agrupamentos em subcategoria e categoria denominadas "Aspectos emocionais e físicos modificando as relaçóes sociais" e "O câncer de mama e suas repercussóes para a mulher jovem", respectivamente.

Conforme prevê a metodologia, na terceira etapa da análise dos dados, foi realizada a integração dos elementos codificados nas duas etapas anteriores (Figura 1).

A descoberta da doença leva ao medo da morte e abala a mulher emocionalmente, fazendo-a repensar seu modo de viver, redefinindo suas prioridades e voltando a atenção para o seu eu. 


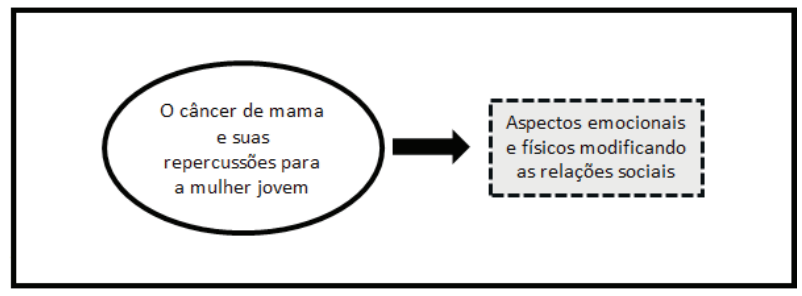

Figura 1. Vivenciando a doença

Quando está dentro do hospital, você começa a vivenciar [a doença], as pessoas começam a falar: Fui curada sete anos! Agora voltou de novo! Fulano está no fígado, na cabeça, voltou mais agressivo; deixa a gente meio que [com medo de morrer] (E11).

Sua visão muda com a doença, você começa a se preocupar mais com você! Começa a se colocar em primeiro lugar! Porque antes, vem minha mãe, filho, marido, e depois, você fala, não, 'peraî', agora é a minha vez! Você começa a se colocar em primeiro lugar (E7)!

Além das consequências advindas do diagnóstico, os tratamentos para a neoplasia modificam o cotidiano da mulher, causando prejuízo nas atividades laborais, e a impossibilidade ou incapacidade de realizá-las é algo que a marginaliza, intimida e deprime, podendo influenciar em sua qualidade de vida.

A vida da gente não gira em torno do tratamento em si. Tem vida profissional, financeira. [Eu] sempre trabalhei, a rotina de ficar em casa é entediante, para quem tem o hábito de trabalhar (E11).

A doença e os tratamentos afetam ainda seu relacionamento interpessoal e a fazem evitar o contato social.

Eu me privei de tudo. Eu saía, bebia, estava em churrasco, festas, fui deixando tudo de lado. Se minha mãe contasse para alguém, eu discutia, eu não queria que ninguém me perguntava, eu sentia mal se alguém viesse falar para mim que eu estava doente, ou o que aconteceu comigo (E1)!

Esses dias, eu encontrei uma amiga, ela falou: Eu te mandei tanta mensagem, você não me respondeu nenhuma! Eu falei: Não foi só você! Foi você e todas as outras! Eu não queria falar! Porque as pessoas ficam com dó, eu não queria que as pessoas pensassem assim de mim, porque eu náo queria estar daquele jeito (E4).

O tratamento quimioterápico interferiu no aspecto físico da jovem mulher fazendo com que ela apresentasse aumento do peso corporal e perda da vaidade.
Sempre fui uma pessoa vaidosa, aí parei com tudo, eu não passava um batom, um lápis, eu não sentia gosto de passar, entendeu? Depois foi passando e tudo foi melhorando, voltei a usar as minhas maquiagens, roupas não servem ainda (risos), nenhuma (E1)!

As depoentes relataram ainda que a alopecia, alteração física também advinda do tratamento quimioterápico, tirou-lhes a vontade de frequentar ambientes públicos $\mathrm{e}$ que os olhares indiscretos geravam incômodo.

Eu tenho vergonha de sair num barzinho, de todo mundo ficar olhando, o cabelo, é um pouco barrado! Eu saía bastante, tinha bastante amizade, fazia de tudo! Tinha uma vida bem ativa! Só que, desde que caiu o cabelo, eu não saí mais! Eu não tive vontade de sair, de me expor! Eu fico mais em casa (E4)!

É ruim o olhar das pessoas, você pode até estar com a calça rasgada, eles olham no cabelo [risos]! Parece que a gente está morrendo, o olhar dos outros que mata a gente (E10)!

Os efeitos indesejáveis da quimioterapia são incontestáveis, mas vale lembrar que o câncer de mama é fortemente temido pelas mulheres por estar associado à perda de um órgão que, em nossa sociedade, está relacionada com a feminilidade. Assim, ter que conviver com a falta desse símbolo e revelar ao companheiro a ausência da mama é um momento difícil para elas.

(...) eu não queria deitar na cama com meu marido, eu não queria ficar perto dele, eu estava com vergonha. Eu falava assim: vou sair fora disso, eu não tenho que viver isso com ele [prática sexual], passar por esse momento [ato sexual]. Eu tinha medo de passar por esse momento, de ter que aceitar o meu corpo como ele está agora. Aceitar uma falta de alguma coisa no meu corpo, porque é falta, eu nasci com o peito, depois ele foi crescendo, eu fui moça, eu tinha aquela coisa e, de repente, você olhar e não vê mais nada? (E2)

Além da perda da mama, as dificuldades em relação às alteraçôes físicas incidem também no braço homolateral à cirurgia, em virtude da retirada da rede linfática, o que leva a restriçôes dos movimentos, afetando as atividades diárias da mulher.

Não limpo casa, não passo roupa, vejo alguma coisa que está pesada e eu náo posso pegar, ter que ficar pedindo para as pessoas, isso é complicado (E6)!

Assim, algumas adversidades dos tratamentos e outras dificuldades relacionadas ao viver com o câncer de mama 
apresentaram-se às mulheres. No entanto, com o decorrer do tempo, elas sentiram que precisavam ir modificando a forma de encarar o problema, de se socializar e continuar suas vidas.

Fui tentando levar a vida normal, social com os meus amigos, os amigos dele, com a minha família (E1)!

Tem restriçóes sim, mas, o que eu puder, eu vou fazer naturalmente e da maneira normal que dá para fazer (E3)!

Eu sempre tentei me manter o mais bem possível perante os outros, eu náo queria que os outros sentissem dó de mim! Eu sempre fui forte e vou continuar sendo [risos] (E4)!

As primeiras [quimio], porque eu tinha um receio, todo mundo falava que ia cair minhas plaquetas e que eu poderia ficar doente com mais facilidade! [...] mas, depois, eu vi que eu já tinha feito várias [quimio] e eu continuava me sentindo bem [...]. Eu trabalho, saio, converso sobre a doença, porque as pessoas acabam te perguntando, mas não porque eu sinto necessidade de falar (E7)!

Final de semana geralmente tem um baile e eu ia muito com o meu marido, então eu não vou pela quantidade de gente! Ele [médico] me explicou que a imunidade fica mais baixa [na quimioterapia] (E8).

(...) embora eu não possa estar saindo, frequento igreja. Na quimioterapia, a gente tem que evitar contato com as pessoas, mudou nesse sentido (E9)!

Ela [médica] falou que não podia ir em lugar com muita gente. Nos primeiros dias, eu não fui não, mas eu vou na igreja! Eu tenho aniversário, eu vou! Não parei não! Eu penso assim, se eu parar, eu mesmo estou me conformando, não é uma doença que vai acabar comigo, que vai me deixar para baixo! Às vezes, a minha irmá me chama para almoçar na casa dela, ou para nós irmos tomar um sorvete, nós vamos $(\mathrm{E} 13)$ !

Outra forma de refúgio e de driblar a doença foi não colocar a enfermidade em primeiro lugar em suas vidas.

Eu acho que pode ser porque eu não vivo a doença, porque se você começa a viver a doença, a possibilidade dela te abalar é muito maior (E7)!

Para conseguir transpor por esse período com menos angústia e sofrimento, foi necessário desenvolver a paciência e a resiliência.
Porque, às vezes, a pessoa imagina que você está passando por um tratamento e acha que você está acabada, destruída, desanimada da vida, não faz as coisas. Mas não, eu tenho saído, conversado, cumprimentado [as pessoas]! Mesmo estando nessa situação, a gente tem que levar da melhor maneira possível que der para levar, não tem por que ficar triste, cabisbaixa, dentro de casa, porque as pessoas vão se surpreender que isso não é o fim do mundo (E3)!

Tem uma palavrinha que é muito difícil que é a paciência. Essa é uma palavrinha que a gente tem que pedir muito a Deus, porque, sem ela, você não consegue nada! Chama paciente, e ele tem que ter muita paciência mesmo, quem está doente que tem que ter mais paciência (E6)!

Elas entenderam ainda a importância de um suporte para enfrentar a doença e os tratamentos, e esse suporte se deu por meio da crença em Deus, da religião, do apoio da família e de conhecidos, o que se tornou fundamental para que essas mulheres enfrentassem a situação que se apresentava a elas e conseguissem transpor os obstáculos que vivenciavam naquele momento.

Eu sempre peço ajuda de Deus, a gente está fazendo o tratamento e Deus me segurou até aqui (E1).

Agora eu voltei a ir à igreja! Do dia que eu comecei o tratamento, domingo eu fui à igreja (E10)!

Em relação à família, me ajudou bastante a questão da gente se aproximar mais. É nessas horas que a gente vê com quem pode contar! Meus irmãos têm ligado, sempre falado comigo. A pessoa vem e se dispóe [ajudar], sendo familiar ou não! Eu tenho visto pessoas que eu nem imaginava, que se dispuseram a me ajudar, da família e mesmo sem ser da família! Outras pessoas que eu tinha amizade de conversar também têm mostrado interesse, que se precisar de alguma coisa, de ajudar. Por isso que eu quero me propor a ajudar também quando passar essa fase, porque eu estou recebendo ajuda positiva, então, lá na frente, eu quero passar essa ajuda para quem precisa (E3)!

(...) eu tive que, além do trastuzumabe, tomar um outro medicamento de alto custo porque náo estava fazendo efeito a quimioterapia. Eu não tinha dinheiro, aí o pessoal da minha igreja disse não, a gente vai fazer uma lista e vai pedir para os produtores de café, que eles ajudam muito o hospital. E aí começou dessa forma, uma mobilização geral, por fim, todo mundo estava me ajudando! Então, na parte social, eu ganhei muito amigo, muita gente 
que gostava de mim e eu nem sabia, que me ajudou, me acolheu [...] (E9).

A gente vem vindo, vai pegando experiência, vai vendo outras pessoas mais novas. Você aprende e conversa com quem já passou e acabou o tratamento e só está naquela medicação que tem que tomar cinco anos. Então, acho que Deus sabe de todas as coisas na hora certa, vai pondo pessoas certas no caminho da gente (E5)!

\section{DISCUSSÃO}

As mulheres apresentaram o estádio esperado para a faixa etária abaixo de 40 anos - tumor ductal infiltrante -, tendo em vista que a maioria estava em tratamento quimioterápico antes de realizar a cirúrgia. Vale ressaltar que, apesar de o estudo ter se desenvolvido na Região Sudeste, onde o diagnóstico tem sido mais precoce ${ }^{16}$, predominaram, ao diagnóstico, os estádios IIIA e IIB; ou seja, mais avançados ${ }^{17}$. Esses resultados corroboram os achados da literatura, que relatam que o diagnóstico nessas pacientes jovens é realizado tardiamente ${ }^{2}$.

Receber o diagnóstico de câncer de mama é difícil, pois geralmente a mulher não está preparada para adoecer e, muito menos, por uma doença tão temida, que, apesar das chances de cura com os tratamentos, estes ainda são assustadores e aterrorizantes, pois modificam a identidade e provocam transformaçóes nos corpos, gerando tristeza, angústia, dor e sofrimento ${ }^{17,18}$.

A neoplasia faz com que essa mulher enxergue a vida com outros olhos. Ela passa a dar prioridade a si mesma, pois, ao assumir os papéis de companheira, filha, amiga, mãe e profissional, acaba deixando-se em segundo plano.

$\mathrm{O}$ câncer de mama provoca alterações funcionais no cotidiano da mulher com câncer de mama, especialmente das mais jovens, que se encontram em fase de ascensão profissional. A doença, muitas vezes, faz com que sua atividade laboral passe a não ser passível de realização, em razão do seu próprio teor, ou pelo fato de os tratamentos e a recuperação física consumirem parte de seu dia, dificultando a conciliação entre ambos.

Esse aspecto influencia ainda nas questóes de ordem financeira, familiar, pessoal e emocional. Estudo com mulheres jovens apontam que a maioria delas está no mercado de trabalho e apresenta mais dificuldades em sua vida financeira e na carreira após o diagnóstico do câncer de mama, o que tem relação com o tempo de afastamento do trabalho ${ }^{19,8}$.

Dessa maneira, o câncer de mama modifica a inserção da mulher dentro da sociedade. Antes da doença, as jovens participantes desta pesquisa referiram uma vida social ativa; frequentavam regularmente bares, festas, churrascos, cinemas, entre outras atividades de lazer; mas, a partir da doença, passaram a ficar mais confinadas a seus ambientes domésticos. É a interação social acontecendo e o self sendo afetado pelos olhares que expressam um sentimento negativo na mulher, por causa das alteraçóes físicas advindas dos tratamentos cirúrgico e quimioterápico.

Em estudo voltado para o câncer de mama, em mulheres com idade mais avançada, apropriar-se de meios para sentir-se bela e atraente é frequentemente relatado pelas participantes ${ }^{20}$, principalmente durante o tratamento, quando ocorrem a mutilação da mama e a alopecia, que levam à diminuição da autoestima.

Porém, neste estudo, esse fato náo ocorreu. As participantes relataram a perda da vaidade e a despreocupação com sua aparência física, focando apenas na cura da neoplasia (na luta pela sobrevivência). Esse fato é também mencionado em outro estudo com mulheres jovens, que apontou a perda da vaidade em função da alopecia e da mastectomia como interferências negativas na vaidade e identidade femininas ${ }^{21}$.

Para as jovens participantes deste estudo, a queda do cabelo afetou o relacionamento interpessoal, o que corrobora as afirmaçóes de alguns estudos que relatam que a perda do cabelo é mais complicada de ser superada do que a mastectomia, uma vez que é mais difícil de ser escondida e/ou disfarçada ${ }^{1,3}$. As mulheres relataram que deixaram de sair de casa para não terem que expor o rosto descaracterizado. Conviver com a falta do cabelo é tido como uma alteração física difícil durante o tratamento ${ }^{3}$, especialmente para as mulheres jovens, uma vez que a sociedade impóe que estas apresentem seus cabelos longos e belos nessa fase de vida; em consequência disso, ocorre o sofrimento em relação à sua queda durante a quimioterapia.

Assim, para algumas mulheres, perder o cabelo representa um momento pior do que quando receberam o diagnóstico do câncer, a perda da mama e a vivência da doença ${ }^{22}$.

Estudos $^{3}$ que tratam da questão da alopecia no câncer de mama, advinda do tratamento quimioterápico, também apresentaram esses achados e apontaram que a sociedade pode influenciar positivamente ou negativamente na maneira como a mulher agirá diante de sua alopecia, a depender de como o outro encara e se reporta a ela durante a vivência desse evento.

Nesse sentido, observa-se que a sociedade influencia no modo como a mulher age frente à doença e às mudanças em seu corpo, advindas dos tratamentos. Se a sociedade tem um comportamento de olhares desaprovadores e curiosos, a mulher tende a se isolar ou mascarar as alteraçóes corporais, usando artifícios para esconder a 
alopecia e, também, a falta da mama. Assim, compreende-se que a sociedade pode tanto encorajar a mulher a enfrentar esse período com menos sofrimento, como torná-lo um momento de mais privaçóes e angústias ${ }^{3}$.

Dessa maneira, grande parte das mulheres deste estudo interpretou que, para os outros, a imagem que elas remetiam era a de uma pessoa doente, necessitada de cuidados, que estava diante da possibilidade da morte e possuía um rosto e corpo descaracterizados e disformes. Diante dessa interpretação, não gostavam do que viam nos olhares dos outros e o produto final dessa interação e interpretação dos símbolos era o afastamento do convívio social, pois os olhares não lhes faziam bem, aumentavam o sofrimento e as faziam lembrar de que estavam condenadas a uma doença que podia levá-las à finitude, apesar de toda luta pela sobrevivência.

Assim como mostram os resultados de estudo recente com mulheres jovens acometidas pelo câncer de mama ${ }^{4}$, os depoimentos das participantes dessa investigaçáo evidenciaram que, na relação íntima do casal, a prática sexual também sofreu abalo por causa da retirada da mama, e o ato sexual chegou a ser interrompido pela dificuldade da mulher em mostrar seu corpo modificado pela doença ao companheiro. Nessa situação, optaram pela fuga, vivenciando um momento de refúgio e recolhimento com o seu eu, para não exporem ao companheiro as modificações do seu corpo.

Após a mastectomia, a mulher, especialmente a mais jovem, demanda um tempo maior para aceitar sua nova imagem corporal, e o companheiro é o elemento-chave para a efetiva retomada da prática sexual entre o casal ${ }^{4}$.

Assim, nas modalidades de tratamento mastectomia, dissecção axilar e radioterapia, observam-se danos à regiáo axilar, com o aumento do risco de prejuízo ao membro superior. A dissecção axilar pode causar dor e redução da amplitude de movimento, diminuiçáo da força muscular e linfedema, implicando em alteraçôes nas atividades diárias, nas laborais e na qualidade de vida. Quando associada à radioterapia, os prejuízos podem ser ainda maiores, em virtude da atrofia muscular e da fibrose que, tardiamente, podem causar diminuiçáo da força e da amplitude de movimento, além de dor e linfedema ${ }^{22}$.

A quimioterapia também ocasiona efeitos colaterais como fadiga, alteraçóes no sono, perda de energia, aumento do peso corporal, problemas psicológicos, redução da força muscular e função cognitiva, o que pode se intensificar quando associada à radioterapia ${ }^{23}$. Assim, as modalidades de tratamento citadas acabam por levar ao comprometimento de tarefas cotidianas que exigem movimentos repetitivos e força, gerando sofrimento à jovem mulher quando ela percebe que está impossibilitada de executar atividades que lhe traziam sustento financeiro ou status social ${ }^{24}$, prejudicando ainda mais suas relaçóes de trabalho.

A restrição dos movimentos desse braço dificulta ainda a realização de tarefas que antes eram simples e faziam parte do seu cotidiano. Sabe-se que as tarefas domésticas são inerentes à figura feminina, mesmo após a conquista de seu espaço no mercado de trabalho. Atividades como lavar e passar roupas, limpar casa e fazer comida, que são tidas como corriqueiras no seu dia a dia, ficam comprometidas a partir da doença e, então, a mulher se sente limitada, impotente e inútil, apresentando um déficit de autonomia, conforme relato apresentado neste estudo.

Essa restrição de movimento afeta também a realização de tarefas voltadas aos seus cuidados pessoais e de higiene como dificuldade em despir-se e vestir-se, tomar banho e lavar as costas, comer, fazer compras e dirigir. As limitaçóes decorrentes da neoplasia mamária influenciam muito a rotina de vida dessas jovens mulheres, assim como sua permanência no trabalho e convívio social ${ }^{25}$.

Mulheres de faixa etária superior à das participantes deste estudo normalmente possuem uma rede familiar ampla (prole já constituída com filhos e netos, parentes mais próximos), o que contribui na ajuda aos seus cuidados e em retornos pós-operatórios. Já as mulheres jovens, por não terem filhos com idade apropriada para ajudá-las nesse sentido e, apesar de terem companheiro, este muitas vezes náo consegue a contento por motivos de trabalho e, assim, esse público acaba por apresentar mais dificuldades nesse sentido. Além disso, muitas relatam preocupação com a constituição de prole futura, que pode ser impossibilitada por conta dos tratamentos aos quais estão submetidas ${ }^{8}$.

Estudo aponta a importância de o companheiro acompanhar sua mulher durante as consultas e o tratamento da neoplasia mamária, visto que este se torna um momento oportuno para a retirada de dúvidas e aumenta as possibilidades de uma reaproximação do casal, em especial, nas questóes relacionadas à prática sexual entre eles, também afetada em detrimento dos tratamentos 4 .

Assim, na tentativa de superarem as adversidades que se apresentavam, as jovens mulheres entenderam ser necessário encarar o problema e viver menos a doença e, gradativamente, foram retomando sua vida social e passaram a ter paciência e resiliência na vivência da neoplasia mamária, o que contribuiu para amenizar a angústia e sofrimento durante esse período, constituindo-se em uma forma de enfrentamento das adversidades.

No retorno ao convívio social, encontraram suporte e revelaram que este se deu por meio de suas crenças em Deus, na religiáo e apoio da família e conhecidos. Estudos apontam que a relação entre o processo saúde/ 
doença e a religiosidade/espiritualidade ajudam as pessoas a administrar de maneira mais satisfatória a vivência da enfermidade, auxilia na aceitaçăo da doença, na cura, e na possibilidade de um futuro, apesar do sofrimento vivenciado. Desse modo, observa-se que a religiosidade/espiritualidade se apresenta como um suporte importante para diminuir o sofrimento gerado pela doença ${ }^{18,26}$, apresentando-se como alternativa de apoio no enfrentamento do tratamento ${ }^{27}$, fato este reforçado pelas participantes desta pesquisa.

Além da religiosidade/espiritualidade, a família apareceu como fonte de apoio para o enfrentamento da enfermidade. Igualmente ao apoio positivo da religiáo e da família, vê-se, nos depoimentos das participantes, a importância do apoio de conhecidos (pessoas com as quais tinham amizade). No câncer de mama, todas as pessoas são importantes, pois o modo como a mulher encara a doença pode ser influenciado pela maneira como ela é recebida e vista no meio em que convive. É a interação social ocorrendo e a mulher fazendo suas interpretaçôes positivas ou negativas dessa interação.

Nesse contexto, as jovens mulheres, mais empoderadas para enfrentar o "mal-estar social", passaram a demonstrar às pessoas que estavam bem e fortes, mesmo diante dos temores e sofrimento que a doença e seus tratamentos poderiam estar lhes causando, uma vez que isso contribuiu para melhorar e encorajar o seu self.

Percebe-se que esse é um momento em que o self aponta ser necessário rever o olhar sobre a situação que está sendo vivenciada e encará-la de modo mais positivo, o que também é visto como uma forma de enfrentamento da doença.

Levando isso em consideração, para as mulheres com câncer de mama, um quesito importante é favorecer esse estreitamento de laços com pessoas que experienciaram o câncer ${ }^{28}$, fato presente nos relatos das participantes deste estudo, o que pode ocorrer também quando os profissionais de saúde as encaminham para grupos de apoio.

\section{CONCLUSÃO}

O comportamento mais agressivo da neoplasia mamária em mulheres jovens e o diagnóstico tardio contribuem para uma classificação diagnóstica do nódulo em estádio mais avançado.

Vivenciar o câncer de mama gerou desespero na mulher jovem em função das alterações que os tratamentos, em especial o cirúrgico e o quimioterápico, provocaram em seu corpo e em sua vida como um todo, modificando suas relações sociais.

O fato de voltarem a atenção para suas vontades, antes deixadas em segundo plano, como a crença em Deus, na religião e o suporte social, foram fatores positivos no enfrentamento da doença e das adversidades, resultado dos tratamentos.

Ao confrontar os achados desta pesquisa com a literatura, observa-se que alguns dos sentimentos apresentados pelas participantes deste estudo permeiam a vida da mulher diagnosticada com câncer de mama, independentemente da idade, como o medo da morte, restriçáo de movimentos com o braço homolateral à cirurgia e dificuldades com as atividades de vida diária, especialmente em casa. No entanto, os achados importantes e que merecem destaque no público jovem foram em relação à alopecia, à mastectomia e ao déficit de autonomia com prejuízo às atividades laborais. Essas afetaram-nas de modo mais intenso, quando comparado ao público com idade mais avançada, merecendo destaque a perda da vaidade feminina.

Essa intensidade diferente com que as jovens mulheres foram afetadas se deve às inserçōes e atuações diferentes em seus papéis sociais. A mulher jovem é namorada, companheira, mãe de filhos ainda dependentes, profissional, enfim, está em plena fase de ascensão profissional, social e afetiva e, diante da doença e seus tratamentos, necessita redefinir seu futuro e projetos de vida.

As questóes relacionadas à sexualidade e à autoimagem são fundamentais para a mulher jovem, porém pouco trabalhadas durante a assistência em saúde prestada, pois o foco principal se dá em torno da doença, fazendo-se importante orientá-las nesse sentido.

Recomendam-se mais estudos nessa área, com mulheres nessa faixa etária, no intuito de maiores contribuiçôes sobre a temática e, também, o uso mais frequente da TFD, de modo a contribuir com o aperfeiçoamento contínuo do método.

\section{CONTRIBUIÇÕES}

Todas as autoras contribuíram na concepçáo e/ ou no planejamento do estudo; na obtenção, análise e interpretação dos dados; assim como na redação e revisão crítica; e aprovaram a versão final a ser publicada.

\section{DECLARAÇÃO DE CONFLITO DE INTERESSES}

Nada a declarar.

\section{FONTES DE FINANCIAMENTO}

Não há.

\section{AGRADECIMENTOS}

Ao Instituto Federal de Educaçáo, Ciência e Tecnologia do Sul de Minas Gerais - Campus Muzambinho - pela 
autorização do afastamento para qualificação, conforme edital de chamada pública CPPD, Muzambinho no. 03/2018.

\section{REFERÊNCIAS}

1. Almeida TG, Comassetto I, Alves KMC, et al. Vivência da mulher jovem com câncer de mama e mastectomizada. Esc Anna Nery. 2015;19(3):432-8. doi: http://doi. org/10.5935/1414-8145.20150057

2. Pereira HFBESA, Viapiana PS, Silva KLT. Aspectos clínicos e patológicos do câncer de mama em mulheres jovens atendidas na FCecon entre 2003 e 2013. Rev Bras Cancerol. 2017;63(2):103-9. doi: https://doi. org/10.32635/2176-9745.RBC.2017v63n2.145

3. Reis APA, Gradim CVC. Alopecia in breast cancer. Rev Enferm UFPE on line. 2018;12(2):447-55. doi: https:/doi. org/10.5205/1981-8963-v12i2a25097p447-455-2018

4. Mairink APAR, Gradim CVC, Gozzo TO, et al. A prática sexual de mulheres jovens em tratamento para o câncer de mama. Esc Anna Nery. 2020;24(3):e20190360. doi: https://doi.org/10.1590/2177-9465-ean-2019-0360

5. Ruddy KJ, Greaney ML, Sprunck-Harrild K, et al. Young women with breast cancer: a focus group study of unmet needs. J Adolesc Young Adult Oncol 2013;2(4):153-60. doi: https://doi.org/10.1089/jayao.2013.0014

6. Di Giacomo D, Ranieri J, Guerra F, et al. Survivorship in young women after early breast cancer: a cross-sectional study of emotional traits along 3-years perspective. Rev Psichiatr. 2019;54(4):160-7. doi: https://doi. org/10.1708/3202.31798

7. Elkum N, Dermime S, Ajarim D, et al. Being 40 or younger is an independent risk factor for relapse in operable breast cancer patients: the Saudi Arabia experience. BMC Cancer. 2007;7:222. doi: https://doi. org/10.1186/1471-2407-7-222

8. Cammarota MC, Santos GC, Daher JC, et al. Reconstrução mamária em mulheres jovens e suas peculiaridades. Rev Bras Cir Plást. 2018;33(1):3-11. doi: http://www.doi. org/10.5935/2177-1235.2018RBCP0002

9. Mead GH. Espiritu, persona y sociedade: desde el punto de vista del condutismo social. Barcelona: Paidos; 1982.

10. Mortensen DC. Teoria de comunicação: textos básicos. São Paulo: Mosaico; 1980. Capítulo 8, Blumer H. A natureza do interacionismo simbólico; p. 119-138.

11. Strauss A, Corbin J. Pesquisa qualitativa: técnicas e procedimentos para o desenvolvimento de teoria fundamentada. 2. ed. Porto Alegre: Artmed; 2008.

12. Engward H. Understanding grounded theory. Nurs Stand. 2013;28(7):37-41. doi: http://www.doi.org/10.7748/ ns2013.10.28.7.37.e7806

13. Tarozzi M. O que é Grounded Theory?: metodologia de pesquisa e de teoria fundamentada nos dados. Petrópolis (RJ): Vozes; 2011.
14. Glaser BG. The grounded theory perspective: conceptualization contrasted with description. Mill Valley (CA): Sociology Press; 2011.

15. Conselho Nacional de Saúde (BR). Resolução no. 466, de 12 de dezembro de 2012. [Dispóe sobre diretrizes e normas regulamentadoras de pesquisas envolvendo seres humanos] [Internet]. Diário Oficial da União, Brasília, DF; 2013 jun. 13. Seção I:59 [acesso 2019 dez 20]. Disponível em: http://conselho.saude.gov.br/ resolucoes/2012/Reso466.pdf

16. Instituto Nacional de Câncer José Alencar Gomes da Silva. Estimativa 2020: incidência de câncer no Brasil. Rio de Janeiro: Inca; 2019.

17. Mineo FLV, Matos LFB, Lima SS, et al. Assistência de enfermagem no tratamento do câncer de mama. Rev Gestão \& Saúde [Internet]. 2013[acesso 2019 dez 12];4(2):2238-60 . Disponível em: https://periodicos. unb.br/index.php/rgs/article/view/256/244

18. Gontijo IBR, Ferreira CB. Sentimentos de mulheres jovens frente ao diagnóstico de câncer de mama feminino. Ciênc Saúde. 2014;7(1):2-10. doi: http://doi. org/10.15448/1983-652X.2014.1.15488

19. Lee CN, Foster RD. Breast reconstruction after mastectomy in young women. Breast Dis. 2006;23:4752. doi: http://doi.org/10.3233/BD-2006-23107

20. Oliveira CL, Sousa FPA, Garcia CL, et al. Cancer and body image: loss of female identity. Rev Rene. 2010;11(Esp):53-60. Disponível em: http://www. revistarene.ufc.br/edicaoespecial/a06v1 1esp_n4.pdf

21. Ferreira DB, Farago PM, Reis PED, et al. Nossa vida após o câncer de mama: percepções e repercussóes sob o olhar do casal. Rev Bras Enferm. 2011;64(3):536-44. doi: https://doi.org/10.1590/S0034-71672011000300018

22. Ferreira MLSM, Aparecido C, Conde CR, et al. Impacto do câncer de mama em mulheres climatéricas. CIAIQ [Internet]. 2017[acesso $2019 \mathrm{dez} 12$ ];2. Disponível em: http://www.proceedings.ciaiq.org/index.php/ciaiq2017/ article/view/1480/1437

23. Islam T, Dahlui M, Majid HA, et al. Factors associated with return to work of breast cancer survivors: a systematic review. BMC Public Health. 2014;14(Suppl 3):S8. doi: https://doi.org/10.1186/1471-2458-14-S3-S8

24. Roberti BFA, Scudeller TT, Amaral MTP. Influência do tratamento do câncer de mama na funcionalidade do membro superior e no retorno à atividade laboral. Rev Ciênc Méd. 2016;25(2):69-76. doi: https://doi. org/10.24220/2318-0897v25n2a3564

25. Rodrigues AC. Alteraçóes de desempenho ocupacional e papéis ocupacionais de mulheres com câncer de mama: uma revisão integrada da literatura [monografia]. Brasília, DF: Escola de Ceilândia, Universidade de Brasília; 2014. 41 p.

26. Ribeiro GS, Campos CS, Anjos ACY. Espiritualidade e religiáo como recursos para o enfrentamento do câncer 
de mama. Rev Pesqui (Univ Fed Estado Rio J, Online). 2019;11(4):849-856. doi: http://doi.org/10.9789/21755361.2019.v11i4.849-856

27. Reis APA, Panobianco MS, Gradim CVC. Enfrentamento de mulheres que vivenciaram o câncer de mama. Rev Enferm Centro-Oeste Mineiro. 2019;9:e2758. doi: http://doi.org/10.19175/recom.v9i0.2758

28. Santana VS, Peres RS. Perdas e ganhos: compreendendo as repercussóes psicológicas do tratamento do câncer de mama. Aletheia [Internet]. 2013[acesso $2019 \mathrm{dez}$ 12];40:31-42. Disponível em: http://pepsic.bvsalud.org/ pdf/aletheia/n40/n40a04.pdf

Recebido em 22/5/2020

Aprovado em 29/6/2020 